\title{
Ensinando Perímetro e Área de Figuras Geométricas Planas Usando o Software Geogebra
}

\author{
Teaching Perimeter and Area of Flat Geometric Figures Using Geogebra Software
}

\author{
Esmênia Furtado Parreira Ferreira ${ }^{1}$ \\ Liamara Scortegagna²
}

\section{Resumo}

Neste artigo apresentamos o Produto Educacional "Ensinando perímetro e área de figuras geométricas planas usando o software Geogebra", resultado da pesquisa de mestrado em Educação Matemática, cuja temática relaciona-se ao uso de Tecnologias Digitais (TD) como instrumento para o ensino e aprendizagem de Geometria. Trata-se de um conjunto de atividades e orientações para os professores do Ensino Fundamental Anos Finais $O$ objetivo da pesquisa é estimular a integração de TD, em específico do software GeoGebra, ao ensino e aprendizagem da Geometria, com foco no estudo de perímetro e área de figuras geométricas planas. A sequência didática de atividades aqui apresentada, refere-se à etapa de experimentação da pesquisa a qual foi validada com alunos $9^{\circ}$ ano do Ensino Fundamental de uma escola da rede municipal. A pesquisa está respaldada nos pressupostos teóricos da Engenharia Didática e na Teoria Antropológica do Didático. Vale ressaltar que há muitos desafios a serem vencidos quanto à integração de TD ao ensino, porém, tal integração pode promover mudanças nas formas de ensinar e aprender, potencializando os resultados.

Palavras-chave: Educação Matemática. Geometria Plana. Tecnologias Digitais. Software GeoGebra.

\begin{abstract}
This article presents the Educational Product "Teaching perimeter and area of flat geometric figures using Geogebra software", as a result of the master's research in Mathematics Education, whose subject relates to the use of Digital Technologies (TD) as an instrument to support teaching and learning of Geometry. It is a set of activities and orientations for teachers of Elementary School - Final Years. The research objective is to stimulate the integration of TD, in GeoGebra software specific, to support teaching and learning activities of Geometry, focusing on the study of perimeter and area of flat geometric figures. The didactic sequence of activities presented here refers to the stage of experimentation of the research which was validated with students 9th grade of

1 Mestre em Educação Matemática, Professora da Educação Básica, Juiz de Fora, MG, Brasil, efparreira@gmail.com.

2 Doutora, Professora do Programa de Pós-Graduação em Educação Matemática - PPGEM, UFJF, Juiz de Fora, MG, Brasil, liamara@ice.ufjf.br.
\end{abstract}


elementary municipal school. The research is supported by the theoretical assumptions of Didactic Engineering and the Anthropological Theory of Didactics. It is worth noting that there are many challenges to be overcome regarding the integration of TD into teaching, but such integration can promote changes in teaching and learning, and the effectiveness enhancing the results.

Key words: Mathematics Education. Flat Geometry. Digital Technologies. GeoGebra Software.

\section{Introdução}

Com o desenvolvimento da pesquisa intitulada: "A Integração das Tecnologias Digitais ao Ensino e Aprendizagem de Geometria no Ensino Fundamental - Anos Finais: uma proposta com foco no estudo de perímetro e área de figuras geométricas planas"3, no Programa de Mestrado Profissional em Educação Matemática da Universidade Federal de Juiz de Fora (UFJF), evidenciou-se a relevância social do conteúdo da pesquisa na formação do indivíduo. Isso se deve à sua aplicabilidade, à importância destacada nos Parâmetros Curriculares Nacionais (PCN), às dificuldades apresentadas pelos discentes e ainda, aos resultados das avaliações em larga escala que apontam 0 ensino da Geometria como um assunto relegado a um segundo plano.

O principal objetivo foi investigar a integração de TD ao processo de ensino e aprendizagem da Geometria, com foco no estudo de perímetro e área de figuras geométricas planas no Ensino Fundamental - Anos Finais, para propor o aprimoramento desse processo. Em específico, averiguou-se de que forma a utilização do software GeoGebra pode contribuir para o estudo do tema em questão.

A investigação é caracterizada pela abordagem de pesquisa qualitativa respaldada nos pressupostos teóricos da Engenharia Didática e a análise dos resultados foi alicerçada na Teoria Antropológica do Didático.

\footnotetext{
${ }^{3}$ A dissertacão está disponível na íntegra em:

http://www.ufj.br/mestradoedumat/files/2011/05/Disserta\%C3\%A7\%C3\%A3o-Esmenia-final.pdf
} 
O objetivo deste artigo é apresentar o Produto Educacional resultante desta pesquisa que se configura em um conjunto de atividades e orientações para os professores do Ensino Fundamental - Anos Finais tendo como suporte tecnológico a utilização do Software GeoGebra. Acreditamos que a integração deste meio, pode dar significado ao aprendizado do aluno e, sobretudo, beneficiar a construção do conhecimento. As atividades foram selecionas, readaptadas e, em seguida, propostas para resolução a alunos do Ensino Fundamental - Anos Finais.

Para apresentar o Produto Educacional, estruturamos o texto iniciando com a descrição do caminho percorrido que teve como ponto de partida a pesquisa de mestrado até o desenvolvimento e validação do produto educacional, ressaltando a conexão entre estes, bem como a relevância e as potencialidades do mesmo no auxílio aos docentes no ensino da Geometria. Em seguida, é apresentado o Produto Educacional e; por fim, algumas observações e considerações.

\section{Caminho: da Pesquisa ao Produto Educacional}

O Produto Educacional, ora aqui apresentado é resultado de uma pesquisa cuja trajetória pautou-se na metodologia da Engenharia Didática que, segundo Artigue (1988), surgiu em didática da matemática na escola francesa, em 1980, através dos trabalhos de Brousseau Guy, passando a estabelecer-se como uma metodologia de pesquisa científica. Partindo da contribuição de Brousseau (apud TEIXEIRA; PASSOS, 2013), Artigue (apud TEIXEIRA; PASSOS, 2013), dentre outros, a Engenharia Didática:

[...] é comparável ao trabalho do engenheiro que, para realizar um projeto, se apoia nos conhecimentos científicos de seu domínio, aceita submeter-se a um controle científico, mas ao mesmo tempo, se encontra obrigado a trabalhar sobre objetos muito mais complexos do que os objetos depurados da ciência e, portanto, a estudar de uma forma prática, com os meios ao seu alcance, problemas que a ciência quer ou não é capaz de se encarregar (ARTIGUE, 1988 apud PASSOS; TEIXEIRA, 2013, p.12-13). 
Nesse contexto, a Engenharia Didática, enquanto vertente de pesquisa qualitativa é aplicada a pesquisas que implicam parcialmente em experimentos de situações de aprendizagem, interligando assim a investigação à ação. Pode ser utilizada em função dupla: para análise de situações didáticas e como metodologia qualitativa de pesquisa em Matemática.

Portanto, essa metodologia pode auxiliar na análise do desenvolvimento do aluno em uma sequência de procedimentos, baseados em suas respostas e condições, em que está submetido para resolver um problema proposto. Isso implica, diretamente, em transformar e adaptar os objetos do saber a ser ensinado. O procedimento experimental da metodologia Engenharia Didática é dividido em quatro fases de investigação, tais como: a $1^{\text {a }}$ fase diz respeito às análises prévias ou preliminares; a $2^{\mathrm{a}}$ fase se relaciona à concepção e à análise a priori; a $3^{a}$ fase é o momento da experimentação e; na $4^{a}$ fase acontece a análise a posteriori e a validação.

A análise preliminar estuda os aspectos gerais relacionados ao tema pesquisado e as possíveis causas do problema de investigação, procurando direcionar a ação do pesquisador para a proposta da sequência didática mais adequada para o objeto de pesquisa. Em nossa pesquisa, esta fase constituiu-se na busca pelo embasamento teórico para fundamentar as atividades. A partir de leituras e estudos abordamos as concepções de alguns autores sobre a Educação Matemática (D'AMBRÓSIO et al, 1991; D'AMBRÓSIO, 2012; DINIZ et al, 1991, BICUDO, 1991 e DANTE et al, 1991), reflexões sobre as tecnologias e a Educação Matemática (KENSKI, 2007 e BORBA; PENTEADO, 2012), descrevemos sobre a Geometria Dinâmica (BRANDÃO; ISOTANI, 2006; SILVA; PENTEADO, 2009 e GRAVINA, 1996) e apresentamos o software GeoGebra (HOHENWARTER; JONES, 2007).

Na segunda fase da investigação, foi realizada uma pesquisa de campo em cinco escolas da Rede Municipal de Ensino de Juiz de Fora, Minas Gerais. Nessa etapa do trabalho foi proposta, para a caracterização do cenário, a aplicação de questionários semiestruturados, envolvendo a participação de 5 diretores, 25 
professores de Matemática e 138 alunos do 9o ano do Ensino Fundamental Anos Finais. A pesquisa foi realizada nos meses de abril e maio de 2016. Tivemos aqui, a pretensão de investigar dados relacionados à disponibilidade e à acessibilidade de recursos tecnológicos para utilização na sala de aula de Matemática, à capacitação dos professores de Matemática para a utilização destes recursos, à frequência da utilização destes recursos pelos docentes, ao interesse dos alunos na inserção das TD no processo de ensino e aprendizagem, bem como os limites e possibilidades dessa integração. Apresentamos também, nesta etapa, o cenário das escolas envolvidas no processo de investigação e a proposta da sequência didática relativa ao conteúdo em estudo com o auxílio do software GeoGebra, uma vez que as análises e o diagnóstico da pesquisa de campo sinalizaram, no cenário das escolas, um ambiente propício e promissor ao uso do software.

$\mathrm{Na}$ terceira fase, foram desenvolvidas as atividades no GeoGebra relativas ao conteúdo em estudo, resultando, posteriormente, no Produto Educacional. Este produto se caracteriza em uma sequência didática que foi desmembrada em três grupos. Para a experimentação das atividades com os alunos, foi escolhida uma das escolas investigadas na segunda fase.

As atividades práticas através do GeoGebra, envolvendo o tema em estudo, foram realizadas em um total de dez encontros. A escolha da escola para a fase de experimentação e validação se deu através da análise dos questionários. Neles, verificou-se um grande envolvimento do diretor da escola, dos professores e dos alunos na pesquisa, além de uma das turmas participantes possuir características especiais (os discentes participam de um projeto de aceleração). Somado a isso, a escola possui um laboratório de informática em boas condições de uso. Este fato atende às necessidades da finalização da investigação prevista nas análises a priori que, entre outros fatores, verificou-se o cenário das instituições quanto ao uso de TD, considerando-se a condução da pesquisa e o uso do software GeoGebra. 
$\mathrm{Na}$ quarta fase foi realizada a análise a posteriori dos resultados da investigação à luz da Teoria do Antropológico Didático, através da apresentação das análises das atividades desenvolvidas pelos alunos. $O$ objetivo desta análise foi validar a hipótese da pesquisa e o Produto Educacional. A Teoria Antropológica do Didático (TAD), ou seja, da praxeologia, concebidos por Chevallard (1998) - tarefa $(T)$, técnica $(\theta)$, tecnologia $(\mathrm{T})$ e teoria $(\Theta)$ é uma prática reflexiva de estudo que nos forneceu subsídios para estudar a construção do saber matemático frente a uma ação pedagógica de um objeto de investigação que permite estabelecer uma conexão entre o saber teórico e o saber prático.

\section{O Produto Educacional "Ensinando Perímetro e Área de Figuras Geométricas Planas Usando o Software Geogebra"4}

O Produto Educacional tem como objetivo, subsidiar os professores de Matemática no ensino de perímetro e área de figuras geométricas planas, com a finalidade de trabalhar a Geometria numa perspectiva dinâmica, visando promover uma melhor aprendizagem. Utilizamos como recurso tecnológico o software GeoGebra, acreditando que a integração deste meio pode dar significado ao aprendizado do aluno e, sobretudo, beneficiar a construção do seu conhecimento.

O referido Produto Educacional, se constitui de uma sequência didática, ora aqui apresentada por um conjunto de atividades que foram selecionadas, readaptadas e validadas a partir da pesquisa desenvolvida no Programa de Mestrado Profissional em Educação Matemática - PPGEM (UFJF). Essas atividades se apresentam em três grupos: duas atividades introdutórias, quatro atividades orientadas e quatro atividades autônomas.

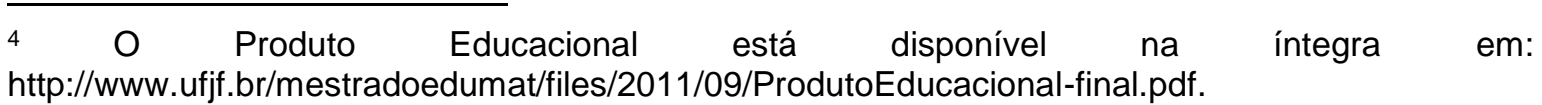




\subsection{Atividades Introdutórias}

As atividades introdutórias são de natureza simples, visam apresentar o software GeoGebra e familiarizar os discentes com as principais ferramentas básicas que serão utilizadas durante o desenvolvimento da sequência didática. Propõe ainda, formalizar conceitos e propriedades de figuras geométricas planas básicas.

Para iniciar a sequência didática, adaptamos duas atividades que chamamos de atividades introdutórias, desenvolvidas por Bezerra e Assis (2011) na XIII Conferência Interamericana de Educação Matemática (CIEM), em Recife, Brasil. Essas atividades objetivam familiarizar os alunos com as principais funções básicas do software GeoGebra através da construção do retângulo e do quadrado. Além disso, busca desenvolver uma visão dinâmica do conceito de construção geométrica e avançar na descoberta de novas construções usando as propriedades das figuras.

Os enunciados das atividades tratam da construção de um retângulo e de um quadrado por meio de suas propriedades com o auxílio do GeoGebra. São de natureza simples, com o objetivo de motivar e preparar os alunos para a aprendizagem com o auxílio do software. Para tanto, é necessário fornecer aos alunos um roteiro com os procedimentos para as construções das figuras geométricas propostas.

A Figura 1 ilustra uma das atividades introdutórias que compõem o Produto Educacional, associada à resolução sugerida. 


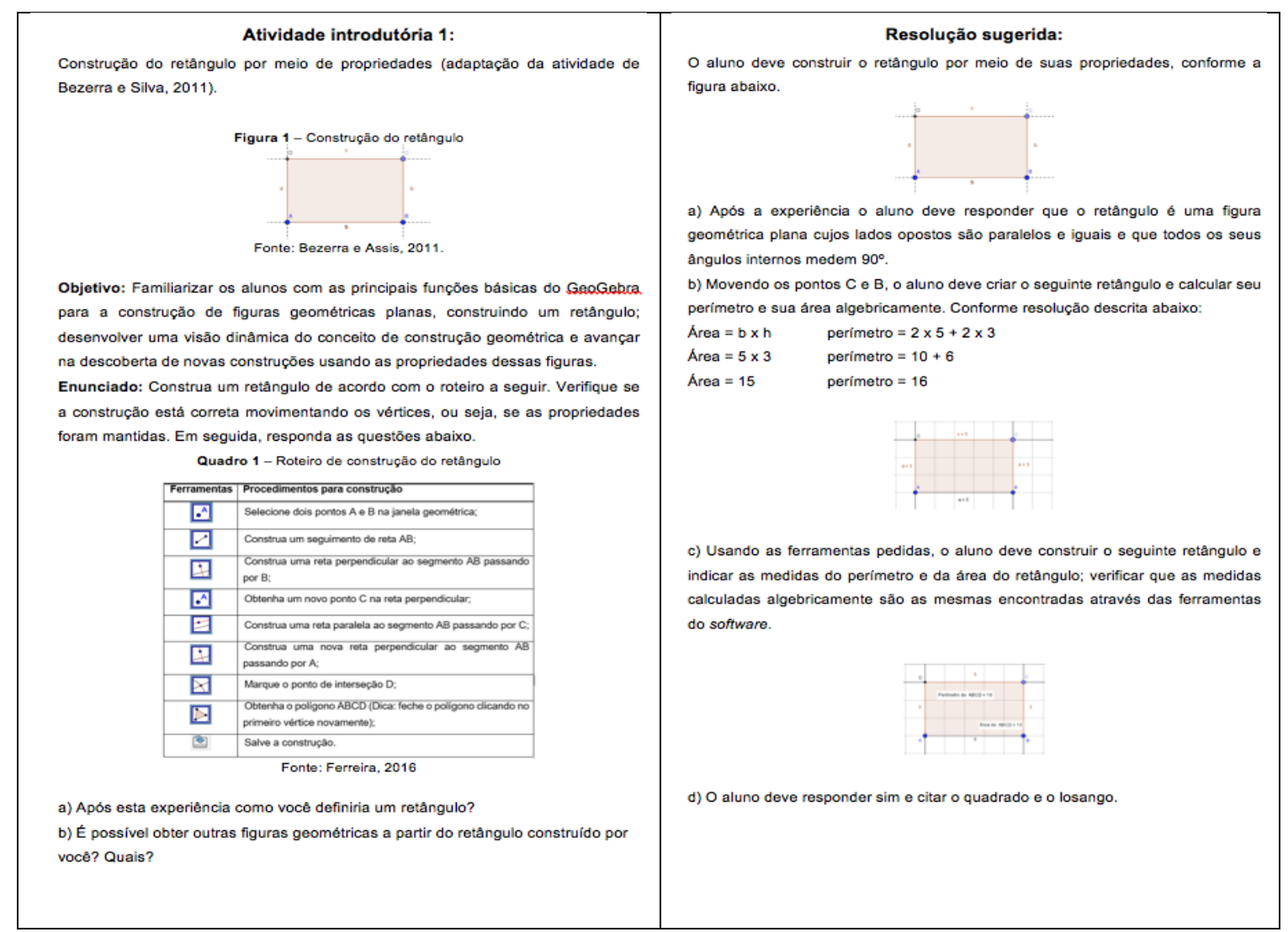

Figura 1: Exemplo de Atividade Introdutória (FERREIRA, 2016).

\subsection{Atividades Orientadas}

Esse grupo de atividades, além de objetivar a familiarização com as ferramentas do software GeoGebra, leva à formalização de conceitos e propriedades. São realizadas sob a forma de atividades orientadas, em que o professor dá suporte aos alunos durante o período da realização das mesmas.

A proposta das atividades orientadas consiste em expor situações investigativas em relação às propriedades de figuras geométricas planas por meio do GeoGebra. Tem como finalidade promover uma melhora na qualidade do ensino e aprendizagem do conteúdo perímetro e área de figuras geométricas planas, além de conhecer e explorar algumas possibilidades do software. $O$ programa possibilita a construção precisa e uma visualização ampla das figuras, permitindo alterar cores, fazer ampliações e conjecturas. Uma função importante, o movimento "arrastar", permite verificar os conceitos e as propriedades. 
Entre os elementos disponíveis no GeoGebra que possibilitam a realização de diversas ações e transformações para a aprendizagem do conteúdo em estudo, selecionamos atividades que envolvam conhecimentos prévios, focando no tema de pesquisa e em algumas ferramentas necessárias para a realização das atividades propostas. Na Figura 2, apresentamos um exemplo de atividade orientada, bem como a resolução sugerida.

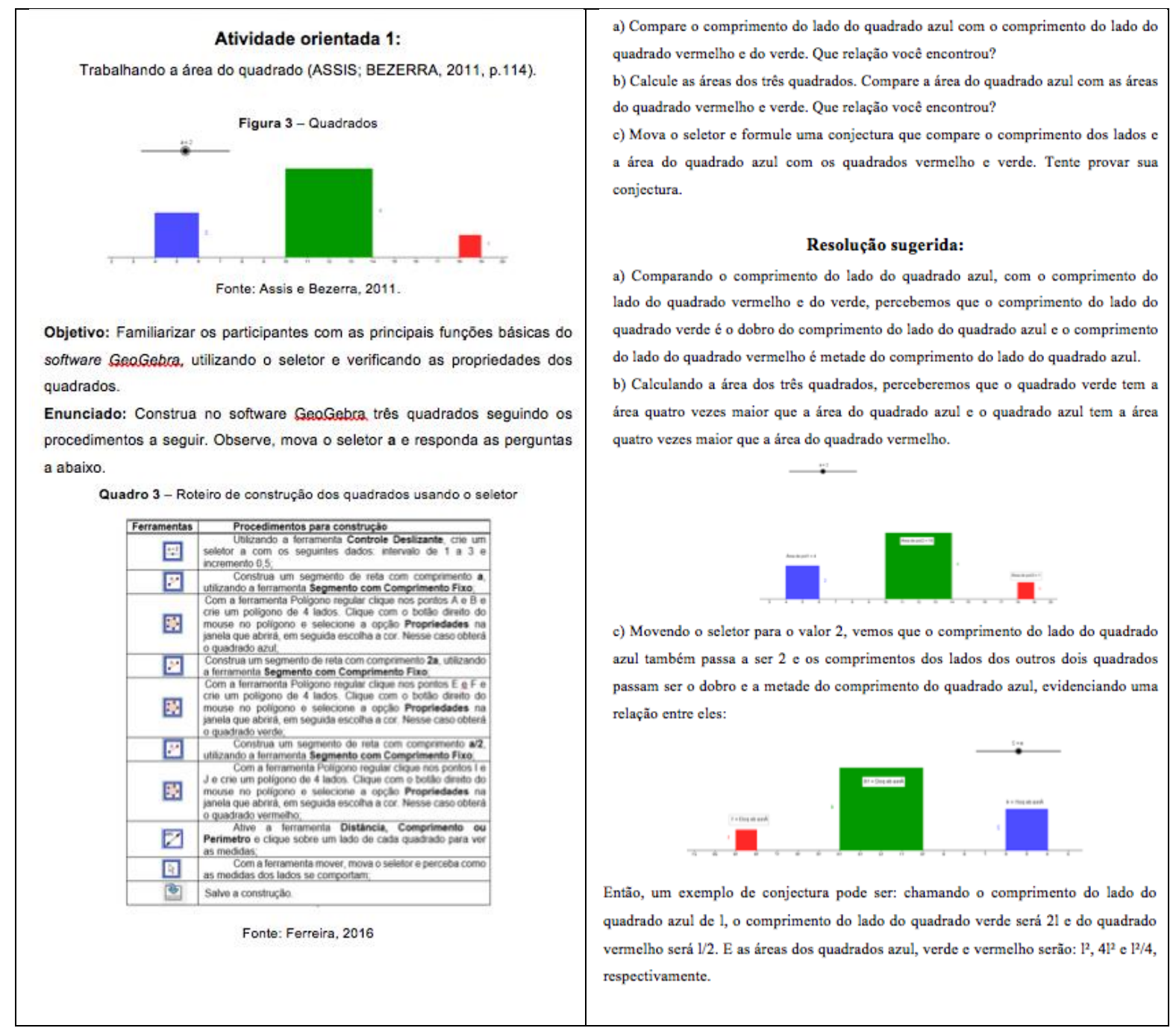

Figura 2: Exemplo de Atividade Orientada (FERREIRA, 2016).

\subsection{Atividades Autônomas}


As atividades autônomas da sequência didática, também têm como finalidade proporcionar a familiarização com o software GeoGebra, mas, além disso, busca desenvolver a autonomia dos discentes ao utilizar as ferramentas e fazer conjecturas relacionadas ao conteúdo em estudo. São utilizadas suas próprias construções, modificando-as através do movimento "arrastar", com o intuito de promover aos alunos o alcance da formalização dos conceitos e das propriedades das principais figuras geométricas planas.

Ao elaborar e adaptar essas atividades, procuramos propor um trabalho investigativo, porém, mais autônomo, que proporcione um ambiente interativo, na busca por promover a colaboração entre os integrantes do grupo e a execução das atividades com o mínimo de intervenção do professor.

$\mathrm{Na}$ figura 3, apresentamos uma das atividades autônomas que compõem o Produto Educacional. 


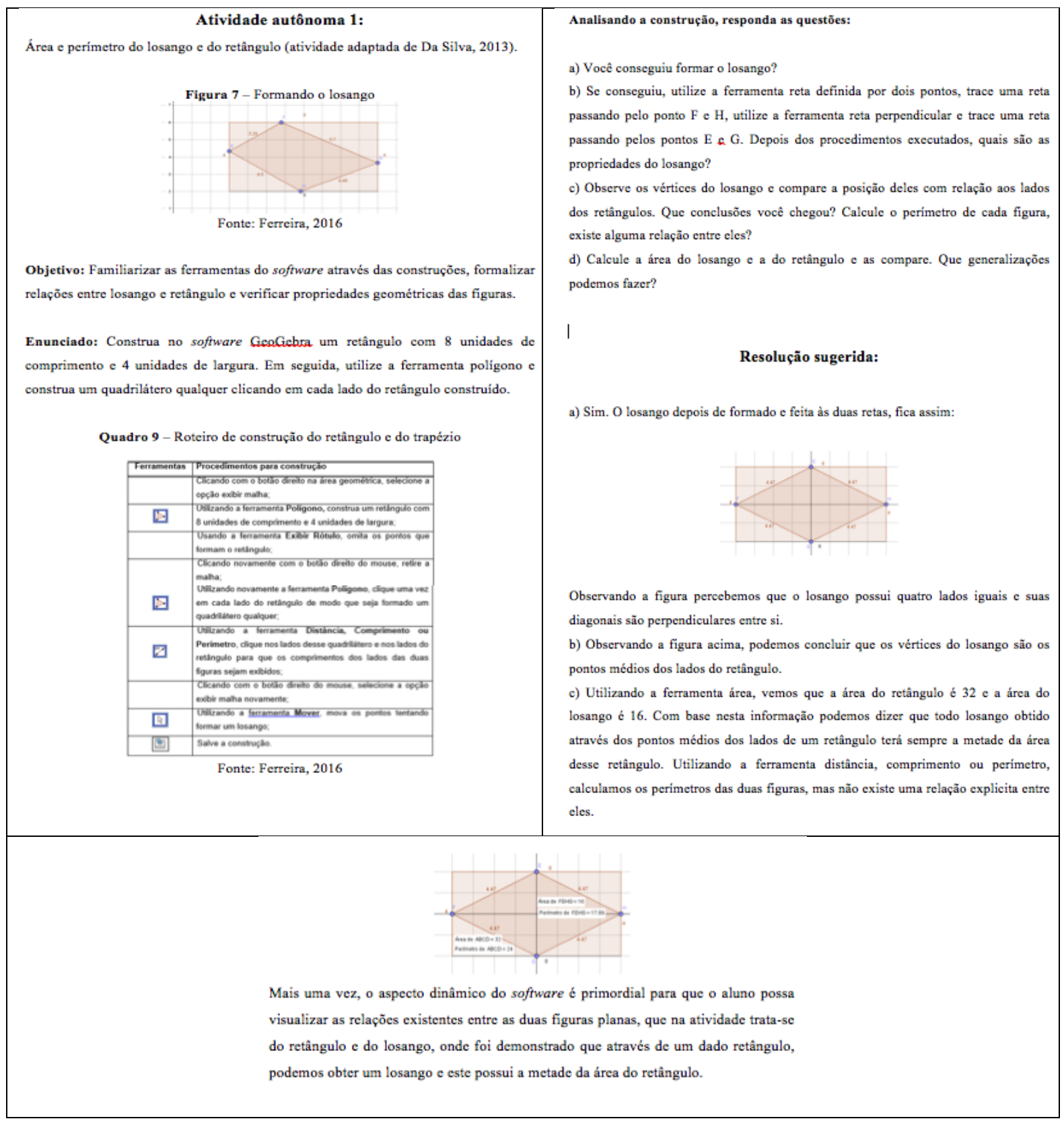

Figura 3: Exemplo de Atividade Autônoma (FERREIRA, 2016).

\section{Observações Importantes aos Professores}

Consideramos importante apresentar algumas observações realizadas durante do desenvolvimento das fases da pesquisa, pois poderão auxiliar os 
professores de Matemática, que objetivam utilizar a sequência didática apresentada neste trabalho, para o ensino da Geometria.

$\mathrm{Na}$ análise a priori, buscamos conhecer a realidade das escolas quanto ao uso de recursos tecnológicos, por meio da síntese do cenário das TD no ensino da Geometria. Foi possível, no decorrer da pesquisa e através da análise do cenário referente ao uso das TD nas escolas, perceber algumas possibilidades e desafios referentes à integração de recursos tecnológicos na educação matemática. Podemos citar como fatores apontados pelos diretores que facilitam o uso de TD para o ensino e aprendizagem da Geometria: os laboratórios disponíveis no turno, a disponibilidade de máquinas e o interesse das escolas nessa integração. Em contrapartida, os professores ressaltaram a necessidade de laboratórios em perfeitas condições de uso, tempo para preparar as aulas, cursos para professores, suporte técnico e a reorganização dos espaços e tempos escolares.

No que diz respeito aos desafios encontrados, ressaltamos que tanto os diretores, quanto os professores, reconhecem como principal fator de inibição dessa integração, a formação profissional do professor, o que sugere a necessidade de revisão do currículo para a formação dos professores. Porém, os docentes acrescentam que as turmas grandes, a necessidade de cumprir planejamento, os alunos indisciplinados e as condições ruins dos laboratórios são desafios enfrentados por eles na tentativa de integrar TD às suas práticas pedagógicas. Contudo, foi evidenciada a relevância da formação profissional. Apesar de trabalharmos com um número reduzido de computadores, não nos deparamos com turmas grandes, permitindo a realização das atividades com êxito. Além disso, o interesse demonstrado pelos alunos em utilizar o software minimizou a indisciplina.

Durante a fase experimental da pesquisa, observamos em relação às condições dos laboratórios que, embora a síntese dos resultados do cenário se mostre favorável a essa integração, encontramos na prática alguns desafios como, por exemplo: das 25 máquinas disponíveis em um laboratório, apenas 13 
estavam funcionando; módulo-aula (50 min.) inadequado; pouca memória dos computadores; e a falta de um sistema interligado em rede, o que dificulta o armazenamento dos arquivos, impedindo o prosseguimento da atividade em aula posterior. Entretanto, para a realização das atividades apresentadas neste Produto Educacional, isso não foi um problema. Os alunos trabalharam em duplas, os arquivos foram enviados por e-mail ou capturados em "pendrive", um a um, ao final de cada encontro e os horários foram reorganizados, provisoriamente, pela direção no período do experimento, permitindo, assim, a realização das atividades.

Quanto às atividades introdutórias, de cunho investigativo, estas proporcionaram uma familiaridade dos alunos com o software GeoGebra e uma visão dinâmica dos objetos construídos, pois foram organizadas na forma de tutorial. As atividades orientadas, também de caráter investigativo, ofereceram, além da familiaridade com o software, uma visão dinâmica das construções geométricas e suas propriedades. Nas atividades autônomas, que segue o gênero investigativo, além da familiarização com o GeoGebra, os discentes desenvolveram uma autonomia ao utilizar as ferramentas e fazer conjecturas relacionadas ao conteúdo em estudo. Ao utilizar-se de suas próprias construções e modificá-las através do movimento "arrastar", os alunos alcançaram a formalização dos conceitos e das propriedades das principais figuras geométricas planas, experimentando e validando suas conjecturas.

Durante os encontros nos quais as atividades foram realizadas, percebemos o desconforto por parte dos alunos em duas das atividades - na atividade orientada 1 e na atividade autônoma 2. Os discentes reclamaram da extensão da tarefa e do processo longo das construções através do roteiro. Isso não foi problema para a finalidade da pesquisa. Mas, para serem desenvolvidas no cotidiano escolar, considera-se a necessidade de uma reavaliação quanto as suas aplicações. $O$ desmembramento em duas etapas ou a adaptação pode ser positivo. 
Destacamos que as atividades foram desenvolvidas com a presença da professora do laboratório de informática e do professor de Matemática das turmas. Este fato foi de suma importância para o desenvolvimento dessa fase da pesquisa, possibilitando a captação dos arquivos, registros fotográficos, realização de observações e anotações.

A sequência didática proposta na pesquisa, por meio das atividades de cunho investigativo, caracterizaram uma alternativa de trabalho com o software GeoGebra, em que as principais ferramentas básicas do software foram conhecidas durante a realização das atividades. Estas se incumbiram de fomentar as experimentações e a possibilidade da integração do software educacional como uma ferramenta que possa contribuir para a melhoria da qualidade do ensino e aprendizagem do tema em estudo e de outros conteúdos geométricos.

\section{Considerações Finais}

Ao desenvolver o Produto Educacional "Ensinando perímetro e área de figuras geométricas planas usando o software GeoGebra", tivemos como objetivo propor aos colegas professores de matemática da Educação Básica, uma sequência didática que poderá auxiliar de forma significativa no ensino e aprendizagem da Geometria para os Anos Finais.

Por meio das atividades geométricas de cunho investigativo, estamos propondo uma alternativa de trabalho com o software GeoGebra, na qual são apresentadas e exploradas as principais ferramentas do software para o estudo de perímetro e área de figuras geométricas planas. Tais ferramentas se incumbem não apenas de fomentar as experimentações e a possibilidade da integração do software educacional como uma alternativa que possa contribuir para a melhoria da qualidade do ensino e aprendizagem do tema em estudo, bem como de estimular a integração de novas tecnologias nas práticas pedagógicas.

O assunto abordado no Produto Educacional é relevante na Educação Básica por sua importância social para a formação do indivíduo, sendo um 
conteúdo fundamental para outros conteúdos como a geometria espacial, por exemplo. Isso se deve à sua grande aplicabilidade, tanto na resolução de problemas de contexto próprio e interdisciplinar, como em situações cotidianas.

Ainda, os PCN (BRASIL,1998) trazem o conteúdo em questão no bloco temático Grandezas e Medidas e destaca sua importância na aprendizagem da Matemática no segundo segmento do Ensino Fundamental. Além dos fatores mencionados, na Matriz de Referência da Prova Brasil para $8^{\text {a }}$ série ( $9^{\circ}$ ano), o bloco temático supracitado trata em seus descritores D 12 e D 13 do conteúdo área e perímetro de figuras geométricas planas. No entanto, os resultados das avaliações em larga escala apontam para o fracasso no ensino e aprendizagem da Matemática e assinalam que a Geometria tem sido relegada a um segundo plano.

Ainda, o produto consta de uma proposta para professores e alunos, que apresenta desafios associados à utilização de Tecnologias Digitais (TD), que podem ser um recurso precioso de ensino e aprendizagem de conteúdos geométricos, aproximando-os das vivências dos discentes no mundo contemporâneo. Esta proposta inclui o estudo das noções que geram o conceito de perímetro e áreas de figuras geométricas planas, a dedução das fórmulas para o cálculo de áreas e a resolução de situações problemas.

Para visualizar as variações transcorridas nas figuras geométricas pelos padrões que as modificam, o GeoGebra é primordial, já que disponibiliza movimentos de simulação inexecutáveis num plano cartesiano, como "arrastar", rotacionar e girar. Tais funções enfatizam a diferença entre desenhar e construir figuras, contribuindo para a aprendizagem dos conceitos, propriedades e regularidades geométricas. Caracteriza-se, portanto, como uma possibilidade metodológica diferenciada e atraente para abordar um assunto relevante para a educação matemática.

Entendemos que esta é mais uma contribuição para o tema em questão e que as pesquisas e discussões não se esgotam nesse estudo e nem na proposta do Produto Educacional. Porém, pretendemos com esse trabalho motivar novas 
práticas pedagógicas que possam provocar reflexões primordiais ao cotidiano escolar. Adicionalmente, destacamos a importância do software GeoGebra como uma ferramenta tecnológica que pode contribuir potencialmente para o ensino e aprendizagem do conteúdo de perímetro e área de figuras geométricas planas utilizando-se de atividades investigativas.

\section{Referências}

ARTIGUE, M. Ingénierie Didactique. Recherches en Didactique des Mathématiques. Grenoble: La Pensée Sauvage-Éditions, v. 9.3, 1998. P. 281-308.

BENTO, H. A.; LAUDARES, J. B. Possibilidades de construção de figuras geométricas planas com o software: GEOGEBRA. Brasília: Edição do autor, 2010.

BEZERRA, M. C.; ASSIS, C. C. Atividades com o GeoGebra: possibilidades para o ensino e aprendizagem da Geometria no Fundamental. XIII Conferência Interamericana de Educação Matemática - CIAEM, Recife, Brasil, 2011.

BICUDO, M. A. V. Matemática, ensino e educação: concepções fundamentais. Temas \& Debates. Sociedade Brasileira de Educação Matemática - SBEM, ano IV, n. 3, Rio Claro, SP, 1991.

BORBA, M. de C.; PENTEADO, M. G. Informática e Educação Matemática (Coleção Tendências em Educação Matemática, 2). 5. ed. Belo Horizonte: Editora Autêntica, 2012.

BRANDÃO, L. O.; ISOTANI, S. Como Usar a Geometria Dinâmica? O Papel do Professor e do Aluno Frente às Novas Tecnologias. CONGRESSO DA SBC, 26; WORKSHOP DE INFORMÁTICA NA ESCOLA, 7, 2006, Campo Grande. Anais... Campo Grande, 2006, p. 120-128.

BRASIL. Ministério da Educação. Secretaria de Educação Fundamental. Parâmetros Curriculares Nacionais: Matemática ( $3^{\circ}$ e $4^{\circ}$ ciclos do ensino fundamental). Brasília: MEC, 1998. Disponível em: <http://portal.mec.gov.br/seb/arquivos/pdf/matematica.pdf>. Acesso em: 16 jun. 2016.

CHEVALLARD. Y. Analyse des pratiques enseignantes et didactique des mathematiques: L'approche anthropologique. Actes de l'U.E. de la Rochelle, 1998. Disponível em: $<$ http://yves.chevallard.free.fr/spip/spip/IMG/pdf/Analyse_des_pratiques_enseignante s.pdf>. Acesso em: 16 jun. 2016. 
D'AMBRÓSIO, U. et al. Matemática, ensino e educação: uma proposta global. Temas \& Debates, Rio Claro, n. 3, p. 1-15, jan. 1991.

D’AMBROSIO, U. Educação Matemática da Teoria á Prática. Campinas, SP, Papirus, 2012.

DA SILVA, E. F. Cálculo de área e perímetro das principais figuras planas: discutindo a adequação de exercícios e problemas para o GeoGebra. 67 p. Trabalho de Conclusão de Curso - (Curso de Licenciatura em Matemática a Distância) - Pitimbu: Departamento de Matemática, UFP; UAB; CCEN, 2013.

DANTE, L. R. et tal. Algumas reflexões sobre educação matemática. Temas \& Debates, Rio Claro, n. 3, p. 43-49, jan. 1991.

DINIZ, M. I. de S. V. et al. Uma visão do ensino da matemática. Temas \& Debates, Rio Claro, n. 3, p. 27-30, jan. 1991.

FERREIRA, E. F. P. A integração das tecnologias digitais ao ensino e aprendizagem de Geometria no Ensino Fundamental - anos finais: uma proposta com foco no estudo de perímetro e área de figuras geométricas planas. 187f. Dissertação (Mestrado Profissional em Educação Matemática) da Universidade Federal de Juiz de Fora, Juiz de Fora - MG, 2016.

GRAVINA, M. A. Geometria Dinâmica uma nova abordagem para o aprendizado da Geometria. SIMPÓSIO BRASILEIRO DE INFORMÁTICA NA EDUCAÇÃO, 7,1996, Belo Horizonte. Anais... Belo Horizonte, 1996, p.1-13.

HOHENWARTER, M. JONES, K. Ways of linking Geometry and algebra: the case of GeoGebra. In: D. Küchemann (Ed.). Procedings of the British Society for Research into Learning Mathematics, 2007, 27 (3), 126-131.

KENSKI, V. M. Educação e Tecnologias: O novo ritmo da informação (Coleção Papirus Educação). Campinas. SP: Papirus, 2007.

SOUZA, B. L; SILVA, S. M. Matemática: possibilidades do uso do GeoGebra nas aulas de Geometria do Ensino Fundamental II. Encontro Mineiro De Educação Matemática, 7. 2015. Anais... São João Del Rei, UFSJ, 2015. P. 1-6. Disponível em: $<$ http://www.ufff.br/emem/files/2015/10/POSSIBILIDADES-DO-USO-DO-GEOGEBRANAS-AULAS-DE-GEOMETRIA-DO-ENSINO-FUNDAMENTAL-II.pdf>. Acesso em: 16 jun. 2016.

TEIXEIRA, P. J. M.; PASSOS, C. C. M. Um pouco da teoria das situações didáticas (tsd) de Guy Brousseau. Zetetiké, Revista de Educação Matemática, FE/ Unicamp, v. 21, n. 39, p. 155-168, jan. / jun. 2013. 